\title{
The Immediate Effects of Foam Rolling and Stretching on Iliotibial Band Stiffness: A Randomized Controlled Trial
}

Talin M Pepper ${ }^{1}$, Jean-Michel Brismée ${ }^{1}$, Phillip S Sizer Jr'1, Jeegisha Kapila1, Gesine H Seeber², Christopher A Huggins ${ }^{3}$, Troy L Hooper ${ }^{1}$

${ }^{1}$ Center for Rehabilitation Research, School of Health Professions, Texas Tech University Health Sciences Center, Lubbock, TX ${ }^{2}$ Center for Rehabilitation Research, School of Health Professions, Texas Tech University Health Sciences Center, Lubbock, TX; University Hospital for Orthopaedics and Trauma Surgery Pius-Hospital, Medical Campus University of Oldenburg, Oldenburg, Germany; Department of Orthopedics, University Medical Center Groningen, University of Groningen, Groningen, The Netherlands, ${ }^{3}$ Center for Rehabilitation Research, School of Health Professions, Texas Tech University Health Sciences Center, Lubbock, TX; Lubbock Christian University, Lubbock, TX

Keywords: tensor fascia latae, shear wave ultrasound elastography, range of motion, hip, adduction

https://doi.org/10.26603/001c.23606

\section{International Journal of Sports Physical Therapy}

Vol. 16, Issue 3, 2021

\section{Background}

Iliotibial Band Syndrome (ITBS) is a common clinical condition likely caused by abnormal compressive forces to the iliotibial band (ITB). Stretching interventions are common in ITBS treatment and may predominantly affect tensor fascia latae (TFL). Another ITBS treatment is foam rolling, which may more directly affect the ITB. Shear wave ultrasound elastography (SWUE) measures real-time soft tissue stiffness, allowing tissue changes to be measured and compared.

\section{Purpose}

To examine effects of foam rolling and iliotibial complex stretching on ITB stiffness at $0^{\circ}$ and $10^{\circ}$ of hip adduction and hip adduction passive range of motion (PROM).

\section{Study Design}

Randomized controlled trial.

\section{Methods}

Data from 11 males (age $=30.5 \pm 9.0$ years, Body Mass Index $(\mathrm{BMI})=27.8 \pm 4.0)$ and 19 females (age $=23.5 \pm 4.9, \mathrm{BMI}=23.2 \pm 2.1$ ) were analyzed for this study. Subjects were randomly assigned to one of three groups: control, stretching, and foam rolling. Shear wave ultrasound elastography measurements included ITB Young's modulus at the mid-thigh, the distal femur and the TFL muscle belly. ITB-to-femur depth was measured at mid-thigh level. Hip adduction PROM was measured from digital images taken during the movement.

\section{Results}

No significant interactions or main effects were found for group or time differences in ITB Young's modulus at the three measured locations. The ITB stiffness at the mid-thigh and distal femur increased with $10^{\circ}$ adduction, but TFL stiffness did not increase. A main effect for adduction PROM was observed, where PROM increased $0.8^{\circ}$ post-treatment $(\mathrm{p}=$ $0.02)$.

\section{Conclusion}

A single episode of stretching and foam rolling does not affect short-term ITB stiffness. The lack of ITB stiffness changes may be from an inadequate intervention stimulus or

\footnotetext{
a Corresponding Author:

Talin M. Pepper

508 Laurelwood Rd.

Burleson, Texas 76028

talin@drpepperpt.com
} 
indicate that the interventions have no impact on ITB stiffness.

\section{Levels of Evidence}

$1 b$

\section{INTRODUCTION}

Iliotibial band syndrome (ITBS) is a common clinical condition characterized by sharp, localized, lateral knee pain, often experienced around $30^{\circ}$ of knee flexion during repetitive knee flexion-extension activities. This entity is reported to account for $10 \%$ of all lower extremity overuse syndromes in runners ${ }^{1}$ and up to $24 \%$ of all overuse syndromes in cyclists. ${ }^{2}$ The pain is often severe enough to result in activity discontinuation. ${ }^{2}$ The type of force causing impingement between the lateral femoral condyle and the iliotibial band (ITB) is debated. Several authors concluded that repetitive ITB movement in an anterior-posterior direction produced friction resulting in microtrauma. ${ }^{3-5}$ Conversely, Fairclough et $\mathrm{al}^{6}$ suggested that the ITB moves in a lateral to medial direction causing lateral knee compression forces. Increased ITB tissue stiffness may increase compression or friction forces along the lateral femoral epicondyle ${ }^{7}$, potentially leading to ITB tissue irritation. ${ }^{4}$

Previous authors have assessed structural changes associated with ITB complex stretching. These investigators questioned the ability of clinical stretching to produce lasting lengthening effects caused by ITB complex stretching maneuvers. ${ }^{8}$ In accordance, a study of in vitro ITB and tensor fascia latae (TFL) complex tissue specimens determined that significantly greater tissue elongation occurs in the proximal region hosting the TFL muscle during a simulated clinical stretch protocol, suggesting that elongation may be due to TFL elongation versus actual ITB lengthening. ${ }^{9}$ Data from that study indicated that the ITB tissue itself was not likely "stretched" during normal clinical stretching protocols. Seeber et $\mathrm{al}^{10}$ in a cadaveric investigation further confirmed this hypothesis. Despite the lack of ITB tissue elongation, global hip adduction ROM improves with hip adduction stretching maneuvers. ${ }^{11}$ TFL-related neuromuscular factors associated with interventions such as stretching and foam rolling might contribute to perceived clinical benefits and increased ROM following ITB stretching. These include easing symptoms that may decrease stiffness in the muscular system components. ${ }^{9}$

An additional treatment commonly used for ITBS symptom management is foam rolling. ${ }^{12-19}$ Prior systematic reviews sought to determine foam rolling treatment effects on joint ROM post-exercise muscle recovery and performance. ${ }^{17,20}$ The findings revealed increased hip extension ROM after one week of foam rolling with return to baseline values after an additional week. ${ }^{21,22}$ Subjects reported pain reduction following foam roller treatment, although pain was reduced in both the treated and non-treated legs, which implies that a mechanism other than myofascial release is responsible for reduced pain responses. ${ }^{17,23,24}$ Despite this, other evidence supporting a potential role for myofascial release suggests it may contribute to reducing ITBS-related pain.

Various studies have investigated plastic, viscoelastic, and piezoelectric connective tissue property changes fol- lowing myofascial release treatments. ${ }^{25-28}$ Trigger points, muscle contractures, and fascial adhesions are suggested to contribute to ITBS pain patterns. Therefore, foam rolling could be effective in "releasing" myofascial restrictions. ${ }^{12}$ However, a narrative literature review suggests this "release" phenomenon does not accurately describe the mechanisms associated with foam rolling. ${ }^{29}$ Instead, foam rolling might promote tissue warming, increasing pliability by transforming tissue into a more fluid-like form and eliminating fibrous adhesions between fascial layers, thus restoring soft tissue extensibility. ${ }^{30}$ Others have suggested that connective tissue may become denser with overuse, but it is unknown if this is related to alterations of collagen composition, fibroblasts, or ground substance. ${ }^{31-34}$ Ajimsha et $\mathrm{al}^{31}$ concluded that further evidence regarding the possible mechanism of action behind myofascial release is needed to make a logical basis for choosing it as an optimal intervention. An in vivo measurement of tissue stiffness using shear wave ultrasound elastography (SWUE) can potentially detect any changes associated with ITB stretching and foam rolling, thereby supporting the insufficient body of evidence surrounding myofascial release techniques.

SWUE is a non-invasive ultrasonographic imaging technique useful for evaluating soft tissue properties by measuring propagation velocity of shear waves produced in biological tissues and ultimately calculating the shear elastic modulus. Although studies regarding reliability, validity, and responsiveness of SWUE for the ITB and TFL are lacking, studies in similar tissues reveal that this method has good to excellent inter- and intra-operator reliability ${ }^{35}$ and that SWUE stiffness measurements correlate well with established testing methods. ${ }^{36,37}$ Previous studies have used SWUE to investigate ITB tissue changes in different loading positions and demonstrated a $32 \%$ increase in ITB stiffness during one-leg standing with increased hip and knee adduction. ${ }^{7}$ In a follow-up study, Tateuchi et al ${ }^{38}$ determined that ITB stiffness increased most with hip extension, adduction, and external rotation during a one-leg standing position. However, it is not known if the ITB stretch produced any change to tissue elastic properties when the tissue is returned to its resting length. ${ }^{38}$ Additionally, it is unknown whether elasticity changes occur when applying a foam rolling intervention.

The purpose of this study was to examine the effects of foam rolling and ITB stretching on ITB stiffness at $0^{\circ}$ and $10^{\circ}$ of hip adduction and hip adduction PROM. Hypotheses include the following: (1) resting ITB stiffness measured with SWUE will not change with clinical stretching techniques; and (2) resting ITB stiffness at $0^{\circ}$ and $10^{\circ}$ of hip adduction measured with SWUE will decrease with application of a foam rolling intervention. 
Table 1: Group demographics (mean and standard deviation) with male (M) and female (F) subjects in each group

\begin{tabular}{lccccc}
\hline Group & Age $(\mathrm{y})$ & Height $(\mathrm{m})$ & Weight $(\mathrm{kg})$ & BMI & Sex (M / F) \\
\hline Foam Rolling $(\mathrm{n}=10)$ & $27.1(6.5)$ & $1.7(0.1)$ & $70.0(13.4)$ & $23.7(3.2)$ & $3 / 7$ \\
Stretching $(\mathrm{n}=10)$ & $26.7(8.6)$ & $1.7(0.1)$ & $76.6(14.8)$ & $25.0(2.9)$ & $4 / 6$ \\
Control $(\mathrm{n}=10)$ & $24.5(7.2)$ & $1.7(0.1)$ & $76.6(19.6)$ & $26.0(4.6)$ & $4 / 6$ \\
\hline
\end{tabular}

\section{METHODS}

\section{EXPERIMENTAL DESIGN}

This study was a single blind, randomized controlled trial (RCT). The independent variables included (1) ITB intervention with three levels (control, stretching, and foam rolling), and (2) time with two levels (before intervention and immediately following intervention). The dependent variables included shear modulus (kilopascals, $\mathrm{kPa}$ ) of the ITB at mid-thigh level and distal thigh level as well as the TFL; all measured at neutral $\left(0^{\circ}\right)$ and $10^{\circ}$ of hip adduction, and (2) hip adduction PROM.

\section{PARTICIPANTS}

The local institutional review board approved this study (\# L19-076). An a priori power analysis to detect changes in stiffness was performed to determine the number of subjects to be included in each group. A previous study ${ }^{38}$ found a moderate effect size (Cohen's $d=0.53$ ) for ITB stiffness between standing with and without hip adduction and contralateral pelvic drop. With alpha $=0.05$ and a moderate effect size of Cohen's $d=0.50$, the number of subjects required to detect a statistically significant within-factors stiffness difference with power $=0.80$ was 30 total subjects. To account for subject attrition and other potential errors, 36 total subjects were recruited from the university's student and employee populations via posted notices of solicitation and in-class recruitment.

Study inclusion criteria included: (1) healthy males and females 18 to 50 years of age; (2) able to provide informed consent for participation. Exclusion criteria were: (1) history of ITB syndrome; (2) regular use of ITB complex stretching or foam rolling; (3) history of hip, knee, or lumbar spine surgery; (4) history of autoimmune disease including fibromyalgia or rheumatoid arthritis; (5) any neurological disease/disorder that impairs lower extremity function (e.g., spasticity) and/or sensation; (6) presence of skin lesions or skin rash on the involved lower extremity; (7) history of deep venous thrombosis; (8) hemophilia; (9) history of hip dysplasia.

Data from 11 males (age $=30.5 \pm 9.0$ years, Body Mass In$\operatorname{dex}(\mathrm{BMI})=27.8 \pm 4.0)$ and 19 females $($ age $=23.5 \pm 4.9$, BMI $=23.2 \pm 2.1$ ) were analyzed for this study (Figure 1 ). All subjects provided informed consent before study participation.

\section{EXPERIMENTAL PROTOCOL}

Subjects were randomly assigned to either control $(n=10)$, stretching $(\mathrm{n}=10)$, or foam rolling $(\mathrm{n}=10)$ groups (Table 1$)$.

The foam rolling group performed an ITB foam rolling technique described previously. ${ }^{13}$ Participants received video instruction regarding uniform foam roller use to standardize the training measures. A foam roller (OPTP PRORoller ${ }^{\circledR}$ Standard; OPTP Minneapolis, MN, USA) with medium firmness and smooth texture was used. Subjects were positioned with the body parallel to the floor and the foam roller placed between the floor and the left thigh. Pressure was adjusted by applying body weight to the roller and using the hands and feet to offset weight for balance as needed. The roller was positioned with its long axis perpendicular to the long axis of the left thigh at the target tissue area (ITB). The subject rolled over the foam roller, where the body was moved back and forth across the foam roller from the greater trochanter to the lateral femoral epicondyle. Participants were instructed to practice up to three times with investigator guidance to achieve the correct foam rolling technique required for this study. Then, the technique was performed on the target tissue using short, kneading-like motions along the length of the tissue and then quickly rolling back to the starting position in one fluid motion. This was repeated for 1-minute, followed by a 30-second rest period and performed for five total repetitions. ${ }^{30}$ Investigators provided feedback to participants regarding correct foam roller technique as needed.

The stretching group performed a stretch described by Fredericson et $\mathrm{al}^{15}$ with a modification of hip external rotation according to Teteuchi et $\mathrm{al}^{38}$. Subjects began by standing upright with the target left leg placed in a hip extended, externally rotated, and adducted position behind the other leg (i.e., right leg). Subjects raised and clasped their hands overhead, exhaled and slowly flexed the trunk in a direction lateral to the opposite side. This motion was continued until an uncomfortable stretch was felt around the greater trochanter of the treatment side hip or until further motion was not possible. Investigators ensured proper positioning for effective ITB complex stretching. The stretch was performed in three bouts of a 7-second submaximal contraction in hip abduction followed by a 15 -second stretch. ${ }^{14}$ Each bout was followed by 30-second rest interval and 3 total bouts were performed.

Subjects in the control group were placed on a treatment table in supine with the hip in neutral rotation for five minutes between measurements.

The left lower extremity was tested due to laboratory setup requirements and limitations in moving the ultrasound device and cameras between each subject. Researchers were blinded to the assigned intervention and 


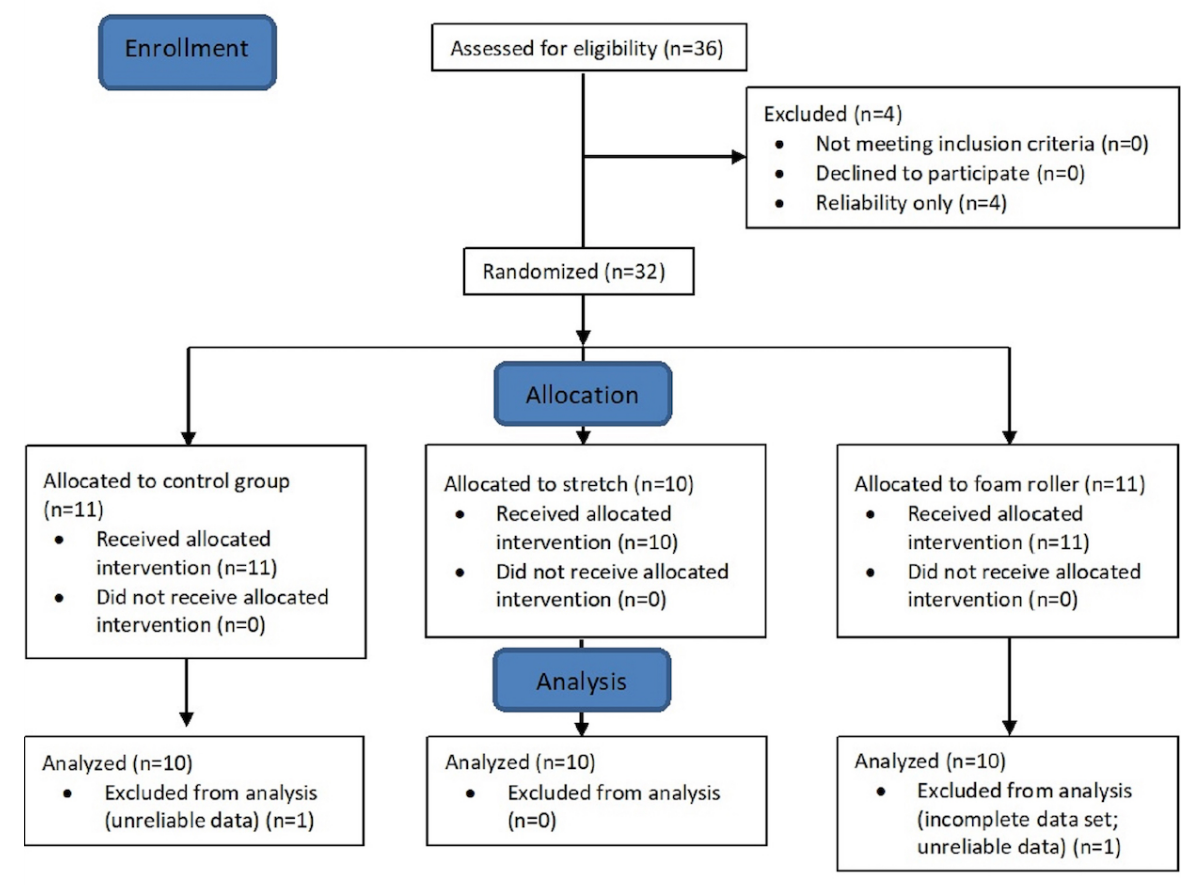

Figure 1: Study enrollment flow chart

the same researchers examined pre- and post-intervention outcomes. Prior to the intervention, tissue stiffness was measured three times at neutral hip adduction $(0)^{\circ}$ and $10^{\circ}$ of hip adduction with the subject in supine. Pilot testing showed that $10^{\circ}$ of hip adduction was sufficient to demonstrate SWUE changes. These measurements were repeated within 10 minutes following the randomized intervention. In addition, hip PROM was recorded pre- and post-intervention.

\section{SHEAR WAVE ULTRASOUND ELASTOGRAPHY}

SWUE measures a soft tissue's stiffness as Young's modulus (kPa). ${ }^{39-42}$ Minimal detectable change for muscle and tendon tissue, respectively, is $1.72 \mathrm{kPa}$ and 32.90 $\mathrm{kPa} .{ }^{35,39,43-45}$ An Aixplorer (SuperSonic Imagine, Version 10.0, Aix-en-Provence, France) ultrasound system measured the ITB Young's modulus at three anatomical locations: (1) lateral mid-thigh, (2) lateral thigh at the level of the patella's superior border, and (3) TFL (Figure 2a and $\underline{2 b})$. The two ITB points were measured with a $15-4 \mathrm{MHz}$ linear transducer with the "Tendon" setting. The TFL was measured halfway between the anterior superior iliac spine (ASIS) and the femoral greater trochanter (10-2 MHz linear transducer with a "Muscle" setting). The mid-thigh location was halfway between the greater trochanter and lateral femoral epicondyle. The transducer was placed along the long axis at each location.

\section{HIP ADDUCTION RANGE OF MOTION}

Hip adduction PROM was determined in real time using an electrogoniometer (Noraxon Ultium, USA). End range hip adduction PROM measurements were performed from video taken from a ceiling-mounted camera (GoPro, Hero5) and analyzed visually.

Markers were placed on bony landmarks at the ASIS bilaterally and on the left lower limb's patella midline for photographic measurement. ${ }^{46}$ End range hip adduction was measured by evaluating when ASIS first began to move. Subjects were placed supine on a plinth, where the contralateral leg was held in a flexed knee position over the measurement leg allowing for full hip adduction. Investigators controlled neutral hip rotation during all hip adduction movements.

\section{STATISTICAL ANALYSIS}

All data analyses were completed using jamovi. ${ }^{47}$ Skewness, kurtosis, Q-Q plots, and Shapiro-Wilk tests were assessed to evaluate data normality, and Levene's test was used to assess homogeneity of variance. Independent ANOVAs were performed to examine baseline differences between groups. To reduce the Type I error risk, the dependent variables were divided into two families with appropriate correction of alpha levels: SWUE measurements (six dependent variables, $\alpha<.008$ ), and hip adduction (one dependent variable, $\alpha<.05$ ). To test whether SWUE values differed between the $0^{\circ}$ and $10^{\circ}$ adduction positions, paired-samples t-tests were performed at all three sites before and after each intervention. Multiple 3 (intervention) x 2 (time) mixed ANOVA analyses were used to determine interaction and main effects of ITB Young's modulus at the patella and thigh levels and the TFL in both $0^{\circ}$ and $10^{\circ}$ of hip adduction and hip adduction PROM. Effect sizes were labeled as small $\left(n_{\mathrm{p}}^{2}=.01\right)$, medium $\left(n_{\mathrm{p}}^{2}=.06\right)$, and large $\left(n_{\mathrm{p}}^{2}=.14\right) .{ }^{48}$ 

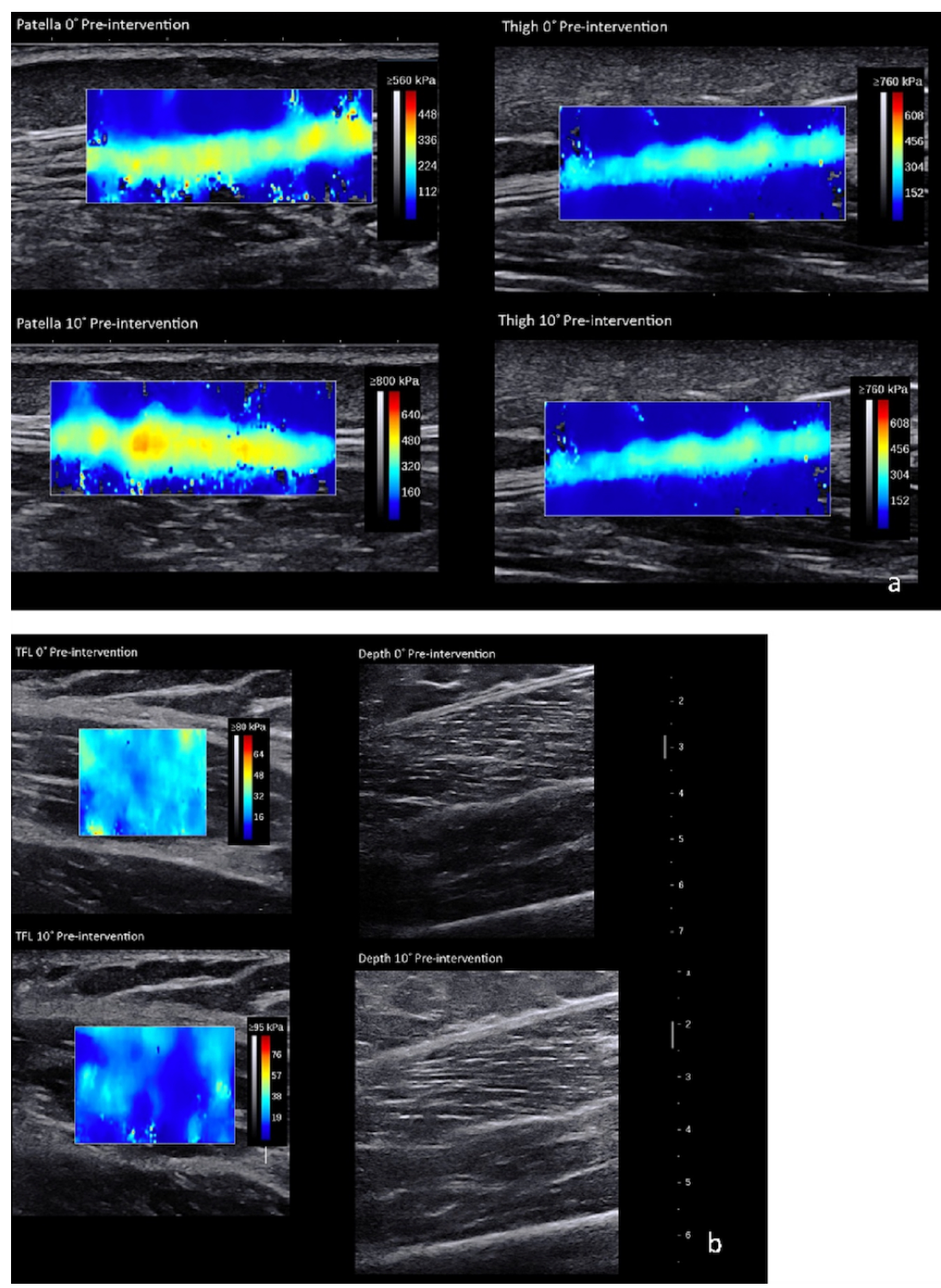

Figure 2: Shear wave elastography and B-mode ultrasound images at each location, at $0^{\circ}$ and $10^{\circ}$ adduction. $\mathrm{TFL}=$ tensor fascia latae

\section{RESULTS}

There were no statistically significant differences among the three groups for age $(p=0.57)$, height $(p=0.76)$, or body mass $(p=0.96)$. No significant interactions or main effects were found for Group or Time differences in ITB complex tissue Young's modulus at the mid-thigh, the superior border of the patella, or the TFL at $0^{\circ}$ or $10^{\circ}$ of hip adduction (Table 2). 
Table 2: Interaction and main effects of time (pre- and -post intervention) and group on stiffness (kPa) of the iliotibial band complex at the level of the patella and midthigh and the tensor fascia latae (TFL) at $0^{\circ}$ and $10^{\circ}$ hip adduction. Data presented as mean (SD).

\begin{tabular}{|c|c|c|c|c|c|c|c|c|c|c|c|c|}
\hline \multirow[b]{2}{*}{$\begin{array}{l}\text { Position and } \\
\text { Location }\end{array}$} & \multirow[b]{2}{*}{$\begin{array}{c}\text { Control* } \\
(n=10)\end{array}$} & \multirow[b]{2}{*}{$\begin{array}{l}\text { Stretching* } \\
(n=10)\end{array}$} & \multirow[b]{2}{*}{$\begin{array}{l}\text { Foam Rolling* } \\
\qquad(n=10)\end{array}$} & \multicolumn{3}{|c|}{ Time by Group Interaction } & \multicolumn{3}{|c|}{ Time Main Effect } & \multicolumn{3}{|c|}{ Group Main Effect } \\
\hline & & & & $\begin{array}{c}\text { F- } \\
\text { Value }\end{array}$ & $\begin{array}{c}\mathrm{p}- \\
\text { Value }\end{array}$ & $\begin{array}{l}\text { Effect Size } \\
\qquad\left(\eta p^{2}\right)\end{array}$ & $\begin{array}{c}\text { F- } \\
\text { Value }\end{array}$ & $\begin{array}{c}\mathrm{p}- \\
\text { Value }\end{array}$ & $\begin{array}{l}\text { Effect Size } \\
\quad(\eta p 2)\end{array}$ & $\begin{array}{c}\text { F- } \\
\text { Value }\end{array}$ & $\begin{array}{c}\mathrm{p}- \\
\text { Value }\end{array}$ & $\begin{array}{l}\text { Effect Size } \\
\quad(\Pi p 2)\end{array}$ \\
\hline \multicolumn{13}{|l|}{$\begin{array}{l}\text { Hip } 0^{\circ} \\
\text { Adduction }\end{array}$} \\
\hline Patella Pre & $257.9(130.2)$ & $\begin{array}{r}182.2 \\
(160.0)\end{array}$ & $233.0(180.8)$ & 0.08 & 0.92 & 0.006 & 0.38 & 0.54 & 0.014 & 0.69 & 0.51 & 0.049 \\
\hline Patella Post & $247.3(140.7)$ & $\begin{array}{r}171.9 \\
(152.8)\end{array}$ & $232.5(143.4)$ & & & & & & & & & \\
\hline Thigh Pre & $218.1(96.3)$ & $\begin{array}{r}231.8 \\
(117.6)\end{array}$ & $283.1(111.6)$ & 0.99 & 0.38 & 0.069 & 0.14 & 0.70 & 0.005 & 0.82 & 0.45 & 0.057 \\
\hline Thigh Post & $216.6(91.9)$ & $244.9(82.4)$ & $259.3(92.4)$ & & & & & & & & & \\
\hline TFL Pre & $24.4(7.3)$ & $22.9(6.3)$ & $23.3(8.0)$ & 0.67 & 0.52 & 0.047 & 0.16 & 0.70 & 0.006 & 0.54 & 0.59 & 0.038 \\
\hline TFL Post & $25.3(4.1)$ & $21.5(7.3)$ & $25.3(7.8)$ & & & & & & & & & \\
\hline \multicolumn{13}{|l|}{$\begin{array}{l}\text { Hip } 10^{\circ} \\
\text { Adduction }\end{array}$} \\
\hline Patella Pre & $473.0(71.7)$ & $\begin{array}{r}332.9 \\
(161.8)\end{array}$ & $380.0(178.5)$ & 0.77 & 0.48 & 0.054 & 0.01 & 0.94 & $<0.001$ & 2.20 & 0.13 & 0.140 \\
\hline Patella Post & $452.2(130.1)$ & $\begin{array}{r}321.5 \\
(180.3)\end{array}$ & $408.1(159.3)$ & & & & & & & & & \\
\hline Thigh Pre & $393.0(74.5)$ & $\begin{array}{r}361.4 \\
(109.7)\end{array}$ & $383.3(84.3)$ & 0.35 & 0.71 & 0.025 & 0.89 & 0.36 & 0.032 & 0.49 & 0.62 & 0.035 \\
\hline Thigh Post & $403.5(90.2)$ & $\begin{array}{r}360.5 \\
(126.1)\end{array}$ & $405.2(91.3)$ & & & & & & & & & \\
\hline TFL Pre & $25.0(7.9)$ & $24.5(10.4)$ & $21.8(4.2)$ & 0.66 & 0.52 & 0.047 & 0.04 & 0.84 & 0.002 & 0.37 & 0.70 & 0.026 \\
\hline TFL Post & $24.8(4.6)$ & $22.1(6.7)$ & $23.4(7.5)$ & & & & & & & & & \\
\hline
\end{tabular}

"Data are presented as mean (SD). 
Table 3: Interaction and main effects of time (pre- and -post intervention) and group on iliotibial band to femur depth (cm) at $0^{\circ}$ and $10^{\circ}$ hip adduction and hip adduction PROM (degrees). Data presented as mean (SD).

\begin{tabular}{|c|c|c|c|c|c|c|c|c|c|c|c|c|}
\hline \multirow[b]{2}{*}{$\begin{array}{l}\text { Position and } \\
\text { Location }\end{array}$} & \multirow[b]{2}{*}{$\begin{array}{c}\text { Control* } \\
(n=10)\end{array}$} & \multirow[b]{2}{*}{$\begin{array}{l}\text { Stretching* } \\
(n=10)\end{array}$} & \multirow[b]{2}{*}{$\begin{array}{c}\text { Foam Rolling* } \\
(n=10)\end{array}$} & \multicolumn{3}{|c|}{ Time by Group Interaction } & \multicolumn{3}{|c|}{ Time Main Effect } & \multicolumn{3}{|c|}{ Group Main Effect } \\
\hline & & & & $\begin{array}{c}\text { F- } \\
\text { Value }\end{array}$ & $\begin{array}{c}\mathrm{p}- \\
\text { Value }\end{array}$ & $\begin{array}{l}\text { Effect Size } \\
\quad(\eta p 2)\end{array}$ & $\begin{array}{c}\text { F- } \\
\text { Value }\end{array}$ & $\begin{array}{c}\mathrm{p}- \\
\text { Value }\end{array}$ & $\begin{array}{l}\text { Effect Size } \\
\quad(\eta p 2)\end{array}$ & $\begin{array}{c}\text { F- } \\
\text { Value }\end{array}$ & $\begin{array}{c}\mathrm{p}- \\
\text { Value }\end{array}$ & $\begin{array}{l}\text { Effect Size } \\
\quad(\text { (П2) }\end{array}$ \\
\hline $\begin{array}{l}\text { Hip Adduction } \\
\text { Pre }\end{array}$ & $6.97(2.55)$ & $7.30(3.18)$ & $8.07(3.49)$ & 0.32 & 0.73 & 0.023 & 6.38 & *.02 & 0.19 & 0.44 & 0.65 & 0.032 \\
\hline $\begin{array}{l}\text { Hip Adduction } \\
\text { Post }\end{array}$ & $7.57(2.10)$ & $8.50(2.65)$ & $8.77(3.09)$ & & & & & & & & & \\
\hline
\end{tabular}

"Statistically significant Bonferroni-corrected p value. 
For hip adduction PROM, no significant interactions were observed. A significant main effect was found for Time, where the mean adduction PROM was $0.8^{\circ}$ greater post-treatment. Additionally, the Group main effect difference was nonsignificant (Table 3).

\section{DISCUSSION}

This study examined ITB and TFL complex stiffness at $0^{\circ}$ and $10^{\circ}$ hip adduction before and immediately following one of three interventions: ITB foam rolling, stretching, or no intervention.

Neither the stretching intervention nor foam rolling altered ITB or TFL stiffness. These results suggest that tissue stiffness does not change with short term static stretching interventions or foam rolling; however, the intervention duration might have been insufficient to elicit tissue change or indicates that the interventions have no impact on healthy subjects ITB and TFL tissue stiffness. Another possibility is that multiple interventions are required. The myofascial plasticity theory may be a reasonable explanation for the lack of stiffness changes in the current study. ${ }^{25}$ Tissue changes occur slowly over time and therefore, may require additional time and intervention repetition to demonstrate changes in ITB stiffness. Wilke et $\mathrm{al}^{49}$ found that anterior thigh stiffness did not change immediately following foam rolling, but decreased after 5 and 10 minutes.

Hip adduction PROM improved post-intervention. However, this change was only $0.8^{\circ}$ and occurred in the control group as well as the two intervention groups, suggesting that it may be due to measurement error and is likely not clinically relevant.
Future research should consider recruiting from a symptomatic population. Doing so may assess whether these results change when pathology is present. This could provide information on the effect of pain on clinical measures of ROM, muscular force production, and end range mobility. Finally, evaluating a longer treatment interval time is necessary to assess changes in these variables with long-term interventions.

\section{CONCLUSION}

The study findings indicate no effect of stretching and foam rolling on short-term ITB stiffness in vivo in healthy subjects, thus supporting previous cadaveric ITB stretching studies. ${ }^{9,10}$ Single bouts of foam rolling and stretching do not change ITB stiffness in healthy subjects and may have limited value in reducing ITB compression. The lack of ITB stiffness changes may be from an inadequate intervention stimulus or indicate that the interventions have no impact on ITB stiffness.

\section{CONFLICT OF INTEREST}

None of the authors have any conflicts of interest to report.

Submitted: December 16, 2019 CDT, Accepted: October 10, 2020 CDT 


\section{REFERENCES}

1. Jakobsen BW, Króner K, Schmidt SA, Kjeldsen A. Prevention of injuries in long-distance runners. Knee Surg Sports Traumatol Arthrosc. 1994;2(4):245-249. do i:10.1007/BF01845597

2. Holmes JC, Pruitt AL, Whalen NJ. Iliotibial band syndrome in cyclists. Am J Sports Med. 1993;21(3):419-424. doi:10.1177/03635465930210031 6

3. Ellis R, Hing W, Reid D. Iliotibial band friction syndrome--a systematic review. Man Ther. 2007;12(3):200-208. doi:10.1016/i.math.2006.08.004

4. Jelsing EJ, Finnoff JT, Cheville AL, Levy BA, Smith J. Sonographic evaluation of the iliotibial band at the lateral femoral epicondyle: does the iliotibial band move? J Ultrasound Med. 2013;32(7):1199-1206. doi:1 $\underline{0.7863 / \text { ultra.32.7.1199 }}$

5. Orchard JW, Fricker PA, Abud AT, Mason BR. Biomechanics of iliotibial band friction syndrome in runners. Am J Sports Med. 1996;24(3):375-379. doi:1 $\underline{0.1177 / 036354659602400321}$

6. Fairclough J, Hayashi K, Toumi H, et al. The functional anatomy of the iliotibial band during flexion and extension of the knee: implications for understanding iliotibial band syndrome. J Anat. 2006;208(3):309-316. doi:10.1111/i.1469-7580.2006.0 $\underline{0531 . \mathrm{x}}$

7. Tateuchi H, Shiratori S, Ichihashi N. The effect of angle and moment of the hip and knee joint on iliotibial band hardness. Gait \& Posture. 2015;41(2):522-528. doi:10.1016/i.gaitpost.2014.12.0 06

8. Falvey EC, Clark RA, Franklyn-Miller A, Bryant AL, Briggs C, McCrory PR. Iliotibial band syndrome: an examination of the evidence behind a number of treatment options. Scand J Med Sci Sports. 2010;20(4):580-587. doi:10.1111/j.1600-0838.2009.00 968.x

9. Wilhelm M, Matthijs O, Browne K, et al. Deformation response of the iliotibial band-tensor fascia lata complex to clinical-grade longitudinal tension loading in-vitro. Int J Sports Phys Ther. 2017;12(1):16-24.

10. Seeber GH, Wilhelm MP, Sizer PS, et al. The tensile behaviors of the iliotibial band - a cadaveric investigation. Int J Sports Phys Ther. 2020;15(3):451-459.
11. Reese NB, Bandy WD. Use of an inclinometer to measure flexibility of the iliotibial band using the Ober test and the modified Ober test: differences in magnitude and reliability of measurements. J Orthop Sports Phys Ther. 2003;33(6):326-330. doi:10.2519/jos pt.2003.33.6.326

12. Fredericson M, Weir A. Practical management of iliotibial band friction syndrome in runners. Clin I Sport Med. 2006;16(3):261-268.

13. Okamoto T, Masuhara M, Ikuta K. Acute effects of self-myofascial release using a foam roller on arterial function: J Strength Cond Res. 2014;28(1):69-73. doi:1 0.1519/JSC.0b013e31829480f5

14. Fredericson M, Guillet M, DeBenedictis L. Quick solutions for iliotibial band syndrome. Phys Sportsmed. 2000;28(2):52-68. doi:10.3810/psm.2000.0 $\underline{2.693}$

15. Fredericson M, White JJ, Macmahon JM, Andriacchi TP. Quantitative analysis of the relative effectiveness of 3 iliotibial band stretches. Arch Phys Med Rehabil. 2002;83(5):589-592.

16. Wang T-G, Jan M-H, Lin K-H, Wang H-K. Assessment of stretching of the iliotibial tract with Ober and modified Ober tests: an ultrasonographic study. Arch Phys Med Rehabil. 2006;87(10):1407-1411. doi:10.1016/j.apmr.2006.06.007

17. Cheatham SW, Kolber MJ, Cain M, Lee M. The effects of self-myofascial release using a foam roll or roller massager on joint range of motion, muscle recovery, and performance: a systematic review. Int J Sports Phys Ther. 2015;10(6):827-838.

18. Doucette SA, Goble EM. The effect of exercise on patellar tracking in lateral patellar compression syndrome. Am J Sports Med. 1992;20(4):434-440. do i:10.1177/036354659202000412

19. Strauss EJ, Kim S, Calcei JG, Park D. Iliotibial band syndrome: evaluation and management. J Am Acad Orthop Surg. 2011;19(12):728-736.

20. Wilke J, Müller A-L, Giesche F, Power G, Ahmedi $\mathrm{H}$, Behm DG. Acute effects of foam rolling on range of motion in healthy adults: a systematic review with multilevel meta-analysis. Sports Med. 2020;50(2):387-402. doi:10.1007/s40279-019-01205-7

21. Bushell JE, Dawson SM, Webster MM. Clinical relevance of foam rolling on hip extension angle in a functional lunge position. J Strength Cond Res. 2015;29(9):2397. doi:10.1519/JSC.0000000000000888 
22. Sullivan KM, Silvey DBJ, Button DC, Behm DG. Roller-massager application to the hamstrings increases sit-and-reach range of motions within five to ten seconds without performance impairments. Int J Sports Phys Ther. 2013;8(3):228-236.

23. Aboodarda S, Spence A, Button DC. Pain pressure threshold of a muscle tender spot increases following local and non-local rolling massage. $B M C$ Musculoskelet Disord. 2015;16(1):265. doi:10.1186/s12 891-015-0729-5

24. Cavanaugh MT, Döweling A, Young JD, et al. An acute session of roller massage prolongs voluntary torque development and diminishes evoked pain. Eur J Appl Physiol. 2017;117(1):109-117. doi:10.1007/s004 21-016-3503-y

25. Schleip R. Fascial plasticity - a new neurobiological explanation: part 1. J Bodyw Mov Ther. 2003;7(1):11-19. doi:10.1016/S1360-8592(02)00 067-0

26. Schleip R, ed. Fascia: The Tensional Network of the Human Body: The Science and Clinical Applications in Manual and Movement Therapy. Edinburgh ; New York: Churchill Livingstone/Elsevier; 2012.

27. Pischinger Alfred, Heine Hartmut. Matrix and Matrix Regulation: Basis for a Holistic Theory in Medicine. Brussels: Haug International; 1991.

28. Greenman PE. Principles of Manual Medicine. Philadelphia, Pa.; London: Lippincott Williams \& Wilkins; 2003.

29. Behm DG, Wilke J. Do self-myofascial release devices release myofascia? Rolling mechanisms: A narrative review. Sports Med. 2019;49(8):1173-1181. $\underline{\mathrm{d}}$ oi:10.1007/s40279-019-01149-y

30. MacDonald GZ, Penney MDH, Mullaley ME, et al. An acute bout of self-myofascial release increases range of motion without a subsequent decrease in muscle activation or force. J Strength Condit Res. 2013;27(3):812-821. doi:10.1519/JSC.0b013e31825c2b c1

31. Ajimsha MS, Al-Mudahka NR, Al-Madzhar JA. Effectiveness of myofascial release: systematic review of randomized controlled trials. J Bodyw Mov Ther. 2015;19(1):102-112. doi:10.1016/j.jbmt.2014.06.001

32. Day JA, Stecco C, Stecco A. Application of Fascial Manipulation (c) technique in chronic shoulder pain-Anatomical basis and clinical implications. $J$ Bodyw Mov Ther. 2009;13(2):128-135. doi:10.1016/i.jb $\underline{\mathrm{mt} .2008 .04 .044}$
33. Stecco A, Gesi M, Stecco C, Stern R. Fascial components of the myofascial pain syndrome. Curr Pain Headache Rep. 2013;17(8):352. doi:10.1007/s119 16-013-0352-9

34. Langevin HM, Fox JR, Koptiuch C, et al. Reduced thoracolumbar fascia shear strain in human chronic low back pain. BMC Musculoskelet Disord. 2011;12:203. doi:10.1186/1471-2474-12-203

35. Zhou J, Yu J, Liu C, Tang C, Zhang Z. Regional elastic properties of the Achilles tendon Is heterogeneously influenced by individual members of the gastrocnemius. Appl Bionics Biomech. 2019;2019:8452717. doi:10.1155/2019/8452717

36. Zhang ZJ, Fu SN. Shear elastic modulus on patellar tendon captured from supersonic shear imaging: Correlation with tangent traction modulus computed from material testing system and testretest reliability. PloS One. 2013;8(6):e68216. doi:10.1 371/journal.pone.0068216

37. Chino K, Takahashi $\mathrm{H}$. The association of muscle and tendon elasticity with passive joint stiffness: In vivo measurements using ultrasound shear wave elastography. Clin Biomech. 2015;30(10):1230-1235. d oi:10.1016/j.clinbiomech.2015.07.014

38. Tateuchi H, Shiratori S, Ichihashi N. The effect of three-dimensional postural change on shear elastic modulus of the iliotibial band. J Electromyogr Kinesiol. 2016;28:137-142. doi:10.1016/i.jelekin.2016.04.006

39. Aubry S, Risson J-R, Kastler A, et al. Biomechanical properties of the calcaneal tendon in vivo assessed by transient shear wave elastography. Skeletal Radiol. 2013;42(8):1143-1150. doi:10.1007/s0 0256-013-1649-9

40. Bercoff J, Tanter M, Fink M. Supersonic shear imaging: a new technique for soft tissue elasticity mapping. IEEE Trans Ultrason Ferroelectr Freq Control. 2004;51(4):396-409. doi:10.1109/TUFFC.2004.129542 $\underline{5}$

41. Gennisson J-L, Rénier M, Catheline S, et al. Acoustoelasticity in soft solids: assessment of the nonlinear shear modulus with the acoustic radiation force. J Acoust Soc Am. 2007;122(6):3211-3219. doi:1 $\underline{0.1121 / 1.2793605}$

42. Sandrin L, Tanter M, Catheline S, Fink M. Shear modulus imaging with 2-D transient elastography. IEEE Trans Ultrason Ferroelectr Freq Control. 2002;49(4):426-435. doi:10.1109/58.996560

43. Eby SF, Song P, Chen S, Chen Q, Greenleaf JF, An $\mathrm{K}-\mathrm{N}$. Validation of shear wave elastography in skeletal muscle. J Biomech. 2013;46(14):2381-2387. doi:10.101 6/i.jbiomech.2013.07.033 
44. Kot BCW, Zhang ZJ, Lee AWC, Leung VYF, Fu SN. Elastic modulus of muscle and tendon with shear wave ultrasound elastography: variations with different technical settings. PLOS ONE.

2012;7(8):e44348. doi:10.1371/journal.pone.0044348

45. Maïsetti O, Hug F, Bouillard K, Nordez A. Characterization of passive elastic properties of the human medial gastrocnemius muscle belly using supersonic shear imaging. J Biomech. 2012;45(6):978-984. doi:10.1016/j.jbiomech.2012.0 $\underline{1.009}$

46. Norkin CC, White DJ. Measurement of Joint Motion: A Guide to Goniometry. F.A. Davis; 2016.
47. The Jamovi Project. [Computer Software]. http s://www.jamovi.org. Published 2019. Accessed April 6, 2020.

48. Portney LG, Watkins MP. Foundations of Clinical Research: Applications to Practice. 3rd edition, [revised]. Upper Saddle River, N.J: Pearson/Prentice Hall; 2015.

49. Wilke J, Niemeyer P, Niederer D, Schleip R, Banzer W. Influence of foam rolling velocity on knee range of motion and tissue stiffness: A randomized, controlled crossover trial. J Sport Rehabil. 2019;28(7):711-715. do $\mathrm{i}: 10.1123 /$ isr.2018-0041 